\title{
Midwife's Role in The Implementation of The Health Minister's Regulation Number 66 of 2014 \\ Through Stimulation, Early Detection and Intervention Activities to Child's Growth Disruption at Public Health Centers of Yogyakarta City
}

\author{
(Peran Bidan pada Pelaksanaan Permenkes Nomor 66 Tahun 2014 \\ Melalui Kegiatan Stimulasi, Deteksi dan Intervensi Dini \\ Gangguan Tumbuh Kembang Anak di Puskesmas Kota Yogyakarta)
}
Ni Luh Gede Wira Yanti, Endang Widyorini, Bernadeta Resti Nurhayati email: niluhgede.wirayanti@yahoo.co.id

Health Law Master Program, Soegijapranata Catholic University of Semarang

\begin{abstract}
Every child had the rights to survive, grow, and well develop to perfect adulthood. However, many children with special needs were factually ignored by their families even they were often considered as family's disgrace. The government, through midwives, could play a role in minimising the risks experienced by children with special needs by doing stimulation, early detection and intervention to child's growth disruption.

This research usedsocio-legal approach with the analytical-descriptive specification. Primary data were obtained from interviews with Head of Health Centers (Puskesmas) of Mergangsan, Jetis and Tegalrejo beside with midwives, integrated service post (posyandu) cadres, and five parents of children with special needs. Secondary data were obtained from books and legal materials related to the research. The data were then qualitatively analysed.

The results showed that the three Health Centers (Puskesmas), namelyMergangsan, Jetis and Tegalrejo, had implemented the Health Minister's Regulation Nr. 66 of 2014. The Health Centers had programs having relations with child's growth that was SDIDTK (stimulation, early detection and intervention of growth disruption). Midwives had performed their roles in stimulation, early detection and intervention of growth disruption thorough examination that was monthly conducted together with posyandu's activities at the Health Centers. Supporting factors of the monitoring implementation of a child's growth, development and development disruption included health care facilities, adequate human resources (health workers), affordable posyandu's costs and cross-sectorial cooperation. The inhibiting factors were low-income family's supports, unfavourable social and economic conditions and mother's knowledge that remained poor.
\end{abstract}

Keywords: children with special needs, early detection, early intervention, stimulation. 


\section{PENDAHULUAN}

Kesehatan merupakan hak yang paling mendasar yang dimiliki oleh setiap individu. Hal ini tertuang dalam Undang-Undang Dasar Tahun 1945 Pasal 28H ayat (1). Hak tersebut diakui dan dilindungi oleh hukum bahkan sejak dalam kandungan. Hak anak merupakan bagian dari hak asasi manusia (HAM) sehingga sejak dalam kandungan, setiap anak berhak hidup, mempertahankan hidup, dan meningkatkan taraf kehidupannya.Hak dasar anak meliputi hak untuk hidup, hak tumbuh dan berkembang secara optimal, hak berpartisipasi sesuai dengan minat dan potensi yang dimiliknya, dan hak terlindungi dari segala tindak kekerasan, diskriminasi, penelantaran dan perlakuan salah. ${ }^{1}$

Kehidupan masa anak-anak adalah cermin dari kehidupan masa depannya. ${ }^{2} P e n i n g k a t a n ~ d a n$ perbaikan upaya kelangsungan, perkembangan dan peningkatan kualitas hidup anak merupakan upaya penting untuk masa depan Indonesia yang lebih baik. Upaya kelangsungan hidup, perkembangan dan peningkatan kualitas anak berperan penting sejak masa dini kehidupan yaitu masa dalam kandungan, bayi dan anak balita. ${ }^{3}$

Anak yang sehat, cerdas dan berahlak mulia merupakan dambaan setiap orangtua. Agar dapat mencapai hal tersebut terdapat berbagai faktor yang mempengaruhi kualitas seorang anak salah satunya dapat dinilai dari proses tumbuh kembang. Proses tumbuh kembang merupakan hasil interaksi faktor genetik dan faktor lingkungan. Faktor genetik atau keturunan adalah faktor yang berhubungan dengan gen yang berasal dari ayah dan ibu, sedangkan faktor lingkungan meliputi lingkungan biologis, fisik, psikologs dan sosial. ${ }^{4}$

Pertumbuhan dan perkembangan mengalami peningkatan yang pesat pada usia dini, yaitu dari nol sampai lima tahun. Masa ini sering disebut sebagai fase "Golden Age". Fase ini merupakan masa yang sangat penting untuk memperhatikan tumbuh kembang anak secara cermat agar sedini mungkin dapat terdeteksi apabila ada kelainan. Selain itu, penanganan kelainan yang sesuai pada fase ini dapat meminimalkan kelainan pertumbuhan dan perkembangan anak yang bersifat permanen. ${ }^{5}$

Sebagian orangtua pasti pernah menemukan beberapa gejala dan gangguan yang dialami buah hatinya. Gangguan pada anak bermula sejak umur enam bulan lebih dan sering terjadi pada usia balita. Gangguan-gangguan tersebut bisa berupa gangguan konsentrasi, gangguan belajar, gangguan bahasa, gangguan disleksia, gangguan berhitung, gangguan menulis, gangguan emosi, gangguan kecemasan, gangguan bipolar, gangguan depresi, gangguan makan dan gangguan tidur. Seringkali hal yang ringan tersebut dianggap remeh, lumrah dan diyakini akan membaik sendiri. Padahal, jika faktor penyebabnya diketahui kita bisa melakukan intervensi untuk mencegahnya menjadi lebih parah. ${ }^{6}$

Di Indonesia istilah kelainan tumbuh kembang ini dikenal dengan anak berkebutuhan khusus atau lebih populer dengan istilah "anak luar biasa". Anak berkebutuhan khusus(ABK) atau disabilitas adalah mereka yang memerlukan penanganan khusus

\footnotetext{
${ }^{1}$ Eko Suryani dan Atik Badi'ah, Asuhan Keperawatan Anak Sehat dan Berkebutuhan Khusus, Yogyakarta, Pustaka Baru Press, hal. 1

${ }^{2}$ Abdul Qodir Shaleh, 2008, Panduan Lengkap Mendeteksi, Memahami dan Mengatasi Masalah-Masalah Kesehatan Anak secara Medis dan Psikologis, Diva Press, Yogyakarta, hal. 15.

${ }^{3}$ Anik Maryunani, 2012, Ilmu Kesehatan Anak dalam Kebidanan, CV. Trans Info Media, Jakarta, hal. 1.

${ }^{4}$ Marmi dan Kukuh Rahardjo, 2014, Asuhan Neonatus, Bayi, Balita dan Anak Prasekolah, Pustaka Pelajar, Yogyakarta, hal. 107.

5lbid.

${ }^{6}$ Maria Ulfa, 2015, Beragam Gangguan Paling Sering Menyerang Anak, FlashBooks, Yogyakarta, hal. 14.
} 
berkaitan dengan kondisinya yang sedikit berbeda dengan anak pada umumnya.Anak-anak yang termasuk ke dalam kelompok berkebutuhan khusus, antara lain: anak dengan cacat fisik (tunawicara, tunarungu, tunanetra dan tunagrahita), anak dengan kekhususan psikis (gifted, hiperaktif dan autis) dan anak dengan kelemahan mental (down syndrome dan kecerdasan di bawah rata-rata). ${ }^{7}$

Instrumen hukum yang mengatur perlindungan hak-hak anak diatur dalam Konvensi PBB tentang Hak-Hak Anak (Convention on The Rights of The Child) Tahun 1983, telah diratifikasi oleh lebih 191 negara. Indonesia sebagai anggota PBB telah meratifikasi peraturan tersebut dengan menerbitkan Kepres Nomor 36 Tahun 1990. Dengan demikian Konvensi PBB tentang Hak Anak tersebut telah menjadikan hukum Indonesia dan mengikat seluruh warga negara Indonesia. Salah satu hak anak tersebut adalah hak untuk tumbuh dan berkembang.

Undang-Undang Nomor 23 Tahun 2002 tentang Perlindungan Anak (untuk selanjutnya disebut UUPA) mengamanatkan bahwa anak berkebutuhan khusus merupakan bagian dari anak Indonesia yang perlu mendapatkan perhatian dan perlindungan dari pemerintah, masyarakat dan keluarga. Kenyataannya, dalam kehidupan sehari-hari anak berkebutuhan khusus belum sepenuhnya mendapatkan haknya untuk berpartisipasi secara penuh dalam kehidupan bermasyarakat. Hal ini terutama terkait dengan masih adanya stigmatisasi, terbatasnya layanan pendidikan, layanan kesehatan, akses pada sarana dan prasarana lingkungan, transportasi dan kesempatan untuk bekerja.

Anak berkebutuhan khusus (ABK) biasanya tampak semenjak lahir, sewaktu bayi dan maksimal saat usia balita. ${ }^{8}$ Anak berkelainan/anak dengan kecacatan merupakan anak yang paling rentan terhadap masalah kesehatan karena lebih berisiko mendapat kekerasan dari orangtua/lingkungannya akibat dari kelainan/kecacatan tersebut, mengalami hambatan dalam pemenuhan kebutuhan gizi, ketidakmampuan anak dalam kebersihan perorangan (kebersihan mulut, kebersihan alat reproduksi, dII) dan cenderung berperilaku beresiko. ${ }^{9}$

Penilaian pertumbuhan dan perkembangan dapat dilakukan sedini mungkin sejak dilahirkan. Deteksi dini merupakan upaya penjaringan yang dilaksanakan secara komprehensif untuk menemukan penyimpangan tumbuh kembang dan mengetahui serta mengenal faktor resiko pada balita. Melalui deteksi dini dapat diketahui penyimpangan tumbuh kembang anak secara dini, sehingga upaya pencegahan, stimulasi, penyembuhan serta pemulihan dapat diberikan dengan indikasi yang jelas pada proses tumbuh-kembang. Upaya-upaya tersebut diberikan untuk mencapai kondisi tumbuh kembang yang optimal. ${ }^{10}$

Pembangunan kesehatan yang menjadikan penanggulangan kematian ibu dan anak sebagai salah satu fokus utamanya adalah menjadikan profesi bidan sebagai ujung tombak utama dalam pembangunan kesehatan. Bidan senantiasa berupaya memberikan pemeliharaan kesehatan yang komperhensif terhadap ibu hamil, ibu menyusui, bayi dan balita khususnya, sehingga mereka tumbuh dan berkembang menjadi insan Indonesia yang sehat jasmani dan rohani. ${ }^{11}$

Sesuai Peraturan Menteri Kesehatan Nomor 369 Tahun 2007 tentang Standar Profesi Bidan pada kompetensi ketujuh keterampilan dasarnya adalah melaksanakan pemantauan dan

\footnotetext{
${ }^{7}$ Aulia Fadhli, 2010, Buku Pintar Kesehatan Anak, Pustaka Anggrek, Yogyakarta, hal. 16.

${ }^{8}$ Afin Murtir, 2014, All About Kesehatan Anak, Trans Idea Publishing, Yogyakarta, hal. 35.

${ }^{9}$ Kementrian Kesehatan RI, 2010, Pedoman Umum Perlindungan Kesehatan Anak Berkebutuhan Khusus.

${ }^{10}$ Marmi dan Kukuh Rahardjo, Op.cit, hal. 151.

${ }^{11}$ Cecep Triwibowo, 2014, Etika dan Hukum Kesehatan, Nuha Medika, Yogyakarta, hal. 25.
} 
menstimulasi tumbuh kembang bayi dan anak. Dalam melaksanakan peranannya bidan bertanggung jawab tidak hanya deteksi dini secara langsung namun dituntut lebih mengoptimalkan kesadaran orangtua dalam pemantauan dan pemberian stimulasi tumbuh kembang sesuai usia sehingga keterlambatan dalam pencapaian tumbuh kembang bisa diminimalkan.

Kewajiban tenaga kesehatan (bidan) dalam melakukan pemantauan terhadap pertumbuhan, perkembangan dan gangguan tumbuh kembang anak telah tertuang dalam Permenkes Nomor 66 Tahun 2014 tentang Pemantauan Pertumbuhan, Perkembangan dan Gangguan Tumbuh Kembang Anak. Hal ini harus diselenggarakan secara komprehensif dan berkualitas melalui kegiatanan yaitu: stimulasi yang memadai, deteksi dini dan intervensi dini gangguan tumbuh kembang anak.

\section{PERUMUSAN MASALAH}

1. Bagaimanakah pelaksanaan Permenkes Nomor 66 Tahun 2014 tentang Pemantauan terhadap Pertumbuhan, Perkembangan dan Gangguan Tumbuh Kembang Anak pada Anak Berkebutuhan Khusus di Puskesmas Kota Yogyakarta?

2. Bagaimanakah pelaksanaan peran bidan dalam melakukan stimulasi, deteksi dan intervensi dini gangguan terhadap pertumbuhan dan perkembangan pada anak berkebutuhan khusus di Puskesmas Kota Yogyakarta?

3. Apakah faktor pendukung dan penghambat yang mempengaruhi peran bidan dalam melakukan stimulasi, deteksi dan intervensi diniterhadapgangguan pertumbuhan dan perkembangan pada anak berkebutuhan khusus di Puskesmas Kota Yogyakarta?

\section{METODE PENELITIAN}

Penelitian ini menggunakan metode yuridis sosiologis dengan pendekatan deskriptif analitis. Jenis data terdiri dari data primer yaitu hasil wawancara responden dan narasumber, serta data sekunder yaitu teori yang diperoleh dari buku serta peraturan perundang-undangan sesuai dengan judul tesis. Penelitian ini dilakukan di 3 puskesmas Kota Yogyakarta yaitu: Puskesmas Mergangsan, Puskesmas Jetis dan Puskesmas Tegalrejo. Metode pengumpulan data yaitu mewawancara dengan narasumber yaitu: Kepala Puskesmas, bidan dan kader posyandu serta responden yaitu orangtua yang memiliki anak berkebutuhan khusus kemudian studi pustaka. Metode analisis data menggunakan kualitatif.

\section{PEMBAHASAN}

1. Pelaksanaan Permenkes Nomor 66 Tahun 2014 tentang Pemantauan Pertumbuhan, Perkembangan dan Gangguan Tumbuh Kembang Anak

Seluruh puskesmas yang diteliti telah melaksanakan pelayanan kesehatan sesuai dengan Permenkes Nomor 66 Tahun 2014 tentang Pemantauan Pertumbuhan, Perkembangan dan Gangguan Tumbuh Kembang Anak. Seluruh puskesmas telah memiliki pelayanan yang berfokus pada tumbuh kembang balita. Tiap puskesmas telah terdapat pelayanan SDIDTK yaitu stimulasi dan deteksi dini tumbuh kembang. Hal ini sesuai dengan Pasal 3 ayat (1) yaitu pemantauan pertumbuhan, perkembangan, dan gangguan tumbuh kembang anak merupakan bagian dari kegiatan pelayanan kesehatan yang dilakukan terhadap Bayi, Anak Balita, dan Anak Prasekolah". 
Pemantauan pertumbuhan dan perkembangan balita tidak hanya dilakukan oleh bidan tetapi juga berkolaborasi dengan ahli gizi dan psikolog. Pertumbuhan dan perkembagan balita biasanya dikaitkan dengan nutrisi yang dikonsumsi balita apakah sudah sesuai dengan nutrisi yang dibutuhkan oleh balita, untuk itu bidan perlu berkolaborasi dengan ahli gizi dan untuk perkembangan balita bidan berkolaborasi dengan psikolog. Dari ketiga puskesmas yang diteiti semuanya memiliki tenaga gizi dan psikolog yang akan membantu bidan dalam melakukan pemantauan tumbuh kembang balita. Hal ini terkait Pasal 3 ayat (3) bahwa pemantauan pertumbuhan, perkembangan, dan gangguan tumbuh kembang anak sebagaimana dimaksud pada ayat (1) diarahkan untuk meningkatkan status kesehatan dan gizi, kognitif, mental, dan psikososial anak. Sehingga pemantauan pertumbuhan dan perkembangan juga mencakup gizi dan psikososial anak sehingga bidan harus berkolaborasi dengan ahli gizi dan psikolog.

Pemantauan pertumbuhan dan perkembangan balita di puskesmas dilakukan secara rutin sesuai jadwal. Menurut tenaga kesehatan (bidan) saat wawancara pemantauan tumbuh kembang disesuaikan dengan usia balita yaitu setiap tiga bulan sekali pada anak usia nol sampai 24 bulan dan setiap enam bulan sekali pada anak usia 24 sampai 59 bulan atau lima tahun. Pemeriksaan tumbuh kembang juga disesuaikan dengan usia balita meliputi pemeriksaan pertumbuhan dengan mengukur tinggi badan, berat badan, lingkar kepala dan lingkar lengan kemudian untuk perkembangan menggunakan indikator KPSP dan DDST dengan melakukan anamnesa ibu dan balita lalu menganjurkan balita melakukan gerakan sesuai tahap perkembangan. Hal ini sesuai dengan Pasal 5 ayat (1) Permenkes tentang Tumbuh Kembang.

Puskesmas merupakan fasilitas pelayanan dasar dimana fasilitas kesehatan yang dimiliki tidak selengkap rumah sakit. Jika dalam pemantauan tumbuh kembang bidan menemukan gangguan tidak dapat ditangani di puskesmas, maka dari hasil penelitian bidan melakukan rujukan ke rumah sakit yang memiliki fasilitas sesuai kebutuhan balita. Balita dengan gangguan tumbuh kembang khususnya jika mengalami gangguan terkait gizi maka puskesmas akan merujuk ke RPG (rumah pemulihan gizi) lalu melakukan pendampingan dan observasi sehingga mengetahui perkembangan kondisi balita. Dari hasil penelitian seluruh puskesmas melakukan hal tersebut. Pasal 7 ayat (1) permenkes tumbuh kembang menyebutkan bahwa dalam hal terdapat kelainan tumbuh kembang pada Anak Balita setelah dilakukan kegiatan sebagaimana dimaksud dalam Pasal 6, tenaga kesehatan harus melakukan rujukan sesuai standar dan ayat (2) Rujukan sebagaimana dimaksud pada ayat (1) dilakukan agar Anak Balita dapat hidup optimal sesuai dengan potensi yang dimilikinya.

Dengan dilaksanakannya Permenkes Nomor 66 Tahun 2014 tentang Pemantauan Pertumbuhan, Perkembangan dan Gangguan Tumbuh Kembang Anak pada seluruh puskesmas yang diteliti diharapkan mampu mengoptimalkan tumbuh kembang anak khususnya anak berkebutuhan khusus.

2. Pelaksanaan Peran Bidan dalam Melakukan Stimulasi, Deteksi dan Intervensi Dini Gangguan Tumbuh Kembang Anak

Pembangunan kesehatan yang menjadikan penanggulangan kematian ibu dan anak sebagai salah satu fokus utamanya adalah menjadikan profesi bidan sebagai ujung tombak utama dalam pembangunan kesehatan. Bidan senantiasa berupaya memberikan pemeliharaan kesehatan yang komperhensif terhadap ibu hamil, ibu menyusui dan khususnya bayi dan balita, sehingga mereka tumbuh dan berkembang menjadi insan 
Indonesia yang sehat jasmani dan rohani. Untuk itu bidan sangat berperan dalam pemantauan pertumbuhan, perkembangan dan gangguan tumbuh kembang balita.

Setiap puskesmas yang diteliti telah memiliki program yaitu SDIDTK yaitu stimulasi dan deteksi dini tumbuh kembang. Dalam program tesebut bidan berkolaborasi dengan dokter umum, ahli gizi dan psikolog, serta kader posyandu di setiap wilayah. Dari hasil penelitan didapatkan bahwa seluruh bidan yang berada di puskesmas tempat penelitian telah melaksanakan perannya sesuai kompetensi dan wewenang. Gangguan tumbuh kembang dapat dicegah sejak dini bahkan sejak dalam kandungan.

Dalam proses pemantauan tumbuh kembang anak diperlukan standar yang tepat. Tujuannya agar proses ini dapat mendeteksi sedini mungkin adanya gangguan pertumbuhan, pemantauan status gizi serta dapat meningkatkan gizi anak. Selain itu standar yang tepat juga akan memperlihatkan dengan jelas dampak kegiatan intervensi media dan nutrisi, serta deteksi dini penyakit yang mendasari gangguan pertumbuhan. Seluruh puskesmas yang diteliti telah memiliki indikator standar untuk melakukan pemantauan tumbuh kembang. Hasil wawancara yang dilakukan oleh penulis terkait penilaian tumbuh kembang, seluruh bidan sepakat untuk pertumbuhan mereka melakukan pemeriksaan antropometri yaitu pengukuran berat badan, tinggi badan, lingkar kepala dan lingkar lengan. Sementara untuk perkembangan tiap puskesmas menggunakan alat ukur berupa DDST atau KPSP. Hal ini sesuai dengan pemantauan tumbuh kembang anak dapat dilakukan dengan beberapa cara diantaranya dengan skrining perkembangan anak menggunakan Denver Development Screening Test (DDST) atau Kuisioner Pra Skrining Perkembangan (KPSP), pengukuran tanda vital anak, serta pemeriksaan antropometri anak. ${ }^{12}$

Seluruh bidan telah melaksanakan perannya dalam melakukan pemantauan gangguan tumbuh kembang melalui kegiatan stimulasi yang memadai, deteksi dan intervensi dini jika terdapat gangguan tumbuh kembang sesuai dengan usia balita dengan menggunakan indikator yang sudah sesuai dengan standar.

3. Faktor Pendukung dan Penghambat yang Mempengaruhi Peran Bidan dalam Melakukan Stimulasi, Deteksi dan Intervensi Dini Gangguan Tumbuh Kembang Anak

a. Faktor Pendukung

1) Ketersediaan Fasilitas Pelayanan Kesehatan

Tersedianya fasilitas yang baik merupakan salah satu faktor pedukung dari pelaksanaan pemantauan pertumbuhan, perkembangan dan gangguan tumbuh kembang anak. Fasilitas yang memadai akan mempermudah bidan maupun tenaga kesehatan lain melakukan pelayanan kesehatan. Fasilitas pelayanan kesehatan yang ada di Puskesmas Mergangsan, Jetis dan Tegalrejo secara umum sudah baik, selain fasilitas di puskesmas, terdapat posyandu di wilayah kerja masing-masing puskesmas untuk membantu bidan melakukan pemantauan tumbuh kembang. Setiap puskesmas yang diteliti telah memiliki program SDIDTK sehingga fasilitas untuk menunjang program tersebut sudah tersedia.

${ }^{12}$ Eko Suryani dan Atik Badi'ah, Asuhan Keperawatan Anak Sehat dan Berkebutuhan Khusus, Pustaka Baru Press, Yogyakarta, hal. 95. 
2) Sumber Daya Manusia (tenaga kesehatan) yang memadai

Ketersediaan tenaga kesehatan yang memadai merupakan faktor pendukung penting dalam mengoptimalkan pertumbuhan dan perkembangan balita dan mencegah gangguan tumbuh kembang. Hal tersebut sesuai dengan Pasal 1 ayat (2) Undang Undang Nomor 36 Tahun 2009 tentang Kesehatan bahwa sumber daya di bidang kesehatan adalah segala bentuk dana, tenaga, perbekalan kesehatan, sediaan farmasi, dan alat-alat kesehatan serta fasilitas pelayanan kesehatan dan teknologi yang dimanfaatkan untuk menyelenggarakan upaya kesehatan yang dilakukan oleh Pemerintah, Pemerintah Daerah dan/ atau masyarakat. Menurut penjelasan dari tiga kepala puskesmas yang ada menyebutkan keseluruhan bidan yang bekerja di puskesmas telah kompeten dalam melakukan pemantauan pertumbuhan dan perkembangan balita. Sumber Daya Kerja Sama Lintas Sektor

Pelaksanaan pemantauan pertumbuhan dan perkembangan di Puskesmas didukung oleh seluruh lintas sektor terkait sehingga seluruh pihak bekerja sama untuk mengoptimalkan tumbuh kembang balita.

3) Biaya posyandu terjangkau

Kegiatan posyandu sangat membantu dalam pemantauan pertumbuhan dan perkembangan balita. Kegiatan ini diadakan setiap bulan sekali oleh kader dengan biaya sukarela. Sehingga hal ini menjadi faktor pendukung dalam pemantauan tumbuh kembang. Dengan biaya yang sukarela diharapkan seluruh orangtua yang memiliki balita datang untuk memantau kesehatan dan tumbuh kembang balitanya.

\section{b. Faktor penghambat}

1) Dukungan keluarga yang masih rendah

Hasil penelitian ditemukan bahwa ibu yang bekerja cenderung tidak memiliki waktu untuk mengikuti posyandu maupun memeriksakan balitanya ke puskesmas. Bagi ibu yang bekerja, balita akan diasuh oleh neneknya. Ibu yang bekerja akan jarang untuk melakukan stimulasi aktif pada balitanya sehingga tidak mengoptimalkan tumbuh kembang balita.

2) Kondisi Sosial dan Ekonomi

Hasil penelitian didapatkan bahwa terdapat keluarga balita yang masih tergolong dalam ekonomi kurang sehingga untuk memeriksakan balitanya ke rumah sakit mereka tidak memiliki biaya. Salah satu orangtua mengatakan bahwa balitanya harus konsultasi ke rumah sakit setiap bulan sementara biaya hidup keluarganya saja sangat terbatas.

Lingkungan sosial juga sangat berpengaruh dalam memotivasi orangtua yang memiliki balita berkebutuhan khusus. Tidak semua orangtua bersedia untuk diwawancarai karena mereka minder dan tertutup dengan kondisi balitanya.

3) Pengetahuan orangtua kurang

Pengetahuan orangtua sangatlah penting dalam pemantauan pertumbuhan dan perkembangan balita. Semakin tinggi pendidikan diharapkan orangtua semakin sadar akan pentingnya memeriksakan kondisi balitanya ke fasilitas kesehatan. 


\section{PENUTUP}

\section{KESIMPULAN}

1. Pelaksanaan Permenkes Nomor 66 Tahun 2014 tentang Pemantauan Pertumbuhan, Perkembangan dan Gangguan Tumbuh Kembang Anaksudah cukup baik dan sesuai, hal ini dapat dibuktikan dengan tenaga kesehatan telah menjalankan tugasnya sesuai dengan kompetensi dan wewenang khususnya untuk bidan dalam hal melakukan stimulasi, deteksi dan intervensi dini tumbuh kembang. Bidan telah melaksanakan stimulasi, deteksi dan intervensi dini tumbuh kembang yang dilakukan di dalam puskesmas saat ibu mengimunisasikan balitanya, dan di luar puskesmas dalam kegiatan posyandu dan dibantu oleh kader posyandu yang telah dilatih. Dalam pelaksanaan deteksi saat posyandu, jika kader menemukan suatu keterlambatan dalam hal pertumbuhan maupun perkembangan maka akan melaporkan kepada puskesmas. Penanganan selanjutnya adalah melakukan pemeriksaan ulang terkait kondisi balita, dan melakukan rujukan ke rumah sakit jika ditemukan kondisi balita yang berkebutuhan khusus.

2. Bidan telah melaksanakan perannya sesuai kompetensi dan kewenangannya dalam melakukan pemantauan pertumbuhan, perkembangan dan gangguan tumbuh kembang anakyakni melakukan stimulasi, deteksi dan intervensi dini tumbuh kembang. Dalam stimulasi bidan melakukan KIE kepada orangtua anak cara mengoptimalkan tumbuh kembang anak dengan stimulasi secara terus menerus, bidan berkolaborasi dengan kader posyandu, gizi dan psikolog dalam mendeteksi gangguan tumbuh kembang anak dengan KPSP dan DDST, kemudian melakukan intervensi dini jika ditemukan gangguan tumbuh kembang sesuai kebutuhan anak.

3. Faktor pendukung pelaksanaan pemantaan pertumbuhan, perkembangan dan gangguan tumbuh kembang anak antara lain: fasilitas pelayanan kesehatan, sumber daya manusia (tenaga kesehatan) yang memadai, biaya posyandu yang terjangkau dan kerja sama lintas sektor. Sementara faktor penghambat adalah dukungan keluarga yang masih rendah, kondisi sosial dan ekonomi yang tidak mendukung dan pengetahuan ibu yang kurang.

\section{SARAN}

\section{Bagi Tenaga Kesehatan Terkait}

Tenaga Kesehatan yang terlibat (bidan, perawat, ahli gizi, psikolog) sebagai tenaga kesehatan yang ada dimasyarakat harus senantiasa mengembangkan dan meningkatkan ilmu pengetahuan dan kemampuan dalam melaksanakan kewenangannya khususnya sebagai seorang bidan dengan mengikuti pelatihan terkait pertumbuhan dan perkembangan yang diharapkan dapat meningkatkan kualitas pelayanan kesehatan. Selain itu harapan penulis agar bidan lebih sering melakukan kunjungan rumah khususnya kepada balita berkebutuhan khusus untuk mengobservasi serta memotivasi orangtua dan keluarga agar senantiasa sabar dan semangat untuk memeriksakan kondisi balitanya.

\section{Puskesmas yang Terlibat dalam Penelitian}

Meningkatkan fasilitas kesehatan sehingga menambah kualitas pelayanan kesehatan. Mempertahankan program terkait SDIDTK yang sudah ada dan bila perlu meningkatkan program sehingga mampu mengoptimalkan tumbuh kembang anak.Selain itu 
puskesmas hendaknya memberikan penyuluhan kepada orangtua balita yang kurang mampu terkait program pemerintah yakni BPJS sehingga anak mereka bisa mendapatkan penanganan dengan biaya ditanggung oleh pemerintah.

\section{Bagi Orangtua Balita dan Keluarga}

Diharapkan bagi ibu yang bekerja khususnya agar memberikan waktu luangnya untuk memeriksakan balitanya ke puskesmas dan mengikuti posyandu secara teratur. Hal ini untuk mengetahui perkembangan tumbuh kembang balita. Keluarga ibu hamil diharapkan ikut berpartisipasi dengan mengantar ibu ke puskesmas agar memberikan dukungan dan semangat bagi ibu.

\section{DAFTAR PUSTAKA}

Abdul Qodir Shaleh, 2008, Panduan Lengkap Mendeteksi, Memahami dan Mengatasi MasalahMasalah Kesehatan Anak secara Medis dan Psikologis, Diva Press, Yogyakarta.

Afin Murtir, 2014, All About Kesehatan Anak, Trans Idea Publishing, Yogyakarta.

Anik Maryunani, 2012, Ilmu Kesehatan Anak dalam Kebidanan, CV. Trans Info Media, Jakarta.

Cecep Triwibowo, 2014, Etika dan Hukum Kesehatan, Nuha Medika, Yogyakarta.

Eko Suryani dan Atik Badi'ah, Asuhan Keperawatan Anak Sehat dan Berkebutuhan Khusus, Pustaka Baru Press, Yogyakarta.

Kementrian Kesehatan RI, 2010, Pedoman Umum Perlindungan Kesehatan Anak Berkebutuhan Khusus.

Maria Ulfa, 2015, Beragam Gangguan Paling Sering Menyerang Anak, FlashBooks, Yogyakarta, Aulia Fadhli, 2010, Buku Pintar Kesehatan Anak, Pustaka Anggrek, Yogyakarta.

Marmi dan Kukuh Rahardjo, 2014, Asuhan Neonatus, Bayi, Balita dan Anak Prasekolah, Pustaka Pelajar, Yogyakarta.

Undang-Undang Dasar 1945

Undang-Undang Nomor 23 Tahun 2002 tentang Perlindungan Anak

Undang-Undang Nomor 36 Tahun 2009 tentang Kesehatan

Permenkes Nomor 369 Tahun 2007 tentang Standar Profesi Bidan

Permenkes Nomor 66 Tahun 2014 tentang Pemantauan Pertumbuhan, Perkembangan dan Gangguan Tumbuh Kembang Anak 